\title{
Familial multiple myeloma. Two more families
}

Research Article

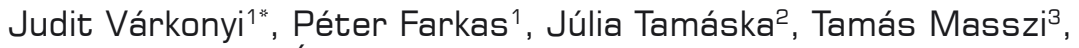 \\ László Gopcsa ${ }^{3}$, Ágnes Padányi ${ }^{4}$, Katalin Rajczy ${ }^{4}$ \\ ${ }^{1}$ Semmelweis University, 3rd Department of Internal Medicine, \\ 1125 Budapest, Hungary \\ ${ }^{2}$ National Medical Center, \\ 1134 Budapest, Hungary \\ ${ }^{3}$ St Laszlo Hospital, \\ 1476 Budapest, Hungary \\ ${ }^{4}$ National Institution of Blood Transfusion, \\ 1113 Budapest, Hungary
}

Received 3 September 2008; Accepted 12 June 2009

\begin{abstract}
The authors report on two multiple myeloma sibling pairs. In the absence of a known disease-specific marker one can only speculate on an explanation: is it because of inherited errors or is it related to the same environmental exposure, or both? In this study HLA typing and metabolizing enzyme polymorphism studies have been carried out with the aim of finding inherited similarities in the siblings or characteristics that might differ from the average population. Sibling pair 1 shared an HLA haplotype. Sibling pair 2 shared only HLAB51, DR4, DRw53, DQ3. Sibling 1/1 was GSTT1 / GSTM1 null and GSTP1 Ile105Val; sibling 1/2 was a GSTT1 / GSTM1 heterozygote and GSTP1 Ile 105Val; sibling 2/1 and 2/2 were GST1 heterozygotes and shared GSTM1 null / GSTP1 Ile 105/le. The siblings had identical light chain or heavy chain secretion, or both. The similarities found in the inherited factors together with the same environmental exposure in the siblings' first 20 years of life imply that the development of the same disease cannot be a coincidence.

Keywords: Henoch-Schönlein purpura • Familial Multiple Myeloma • Genetic polymorphism • Susceptibility to cancer

(c) Versita Warsaw and Springer-Verlag Berlin Heidelberg.
\end{abstract}

\section{Introduction}

It is always an intriguing puzzle when there is a frequent occurrence of a non-contagious disease in the same family. This is the case in familial multiple myeloma (MM) with the involvement of siblings in most instances. Multiple myeloma is responsible for one percent of all cancer deaths in the western world. Familial myeloma however is a rare entity.

In the absence of a disease-specific alteration - like that of the bcr/abl gene rearrangement in chronic myeloid leukemia - one can only speculate on the reasons for such a development. Did it develop as a consequence of inherited errors or result from environmental damage the siblings were exposed to in their early years living together in the same environment, or both? It is of the utmost importance therefore to publish as many as possible of the cases found all over the world including details of their biological characteristics. In this spirit herewith the authors present two more families with multiple myeloma in siblings.

\section{Material and Methods}

HLA-A, -B and -C typing was performed by the standard NIH micro-lymphocytotoxicity method [1]. HLA-DR and -DQ antigens were determined by DNA based PCRSSP technique [2]. GSTM1 GSTT1 genotyping was performed by multiplex PCR essentially according to earlier enzyme polymorphism studies [3]. GSTP1 Ile105Val genotypes were identified according to the method of Ozawa et al. except that Thermoprime Plus 
Table 1. Clinical data of the two multiple myeloma sibling pairs.

\begin{tabular}{l|llllll}
\hline Siblings & gender & Age* $^{*}$ & paraprotein & Blood group & Karyotype/FISH & Environmental exposure \\
\hline \hline $1 / 1$ & F & 68 & IgG kappa & B- & $\mathrm{N} / \mathrm{N}$ & Passive smoking in childhood \\
$1 / 2$ & $\mathrm{M}$ & 66 & IgG kappa & $\mathrm{A}+$ & $\mathrm{N} / \mathrm{N}$ & Passive smoking in childhood \\
$2 / 1$ & $\mathrm{M}$ & 54 & Kappa light chain & $\mathrm{O}+$ & $\mathrm{N} / \mathrm{N}$ & Aromatic paints \\
$2 / 2$ & $\mathrm{M}$ & 48 & IgG kappa & $\mathrm{B}+$ & $\mathrm{N} /+11$ & Aromatic paints, benzene \\
\hline
\end{tabular}

Age*: age at diagnosis, N: normal

Table 2. HLA-RESULTS.

\begin{tabular}{|c|c|c|c|c|c|c|c|}
\hline \multirow[t]{2}{*}{ Sibling 1/1 } & \multicolumn{7}{|l|}{$(F)$} \\
\hline & A & B & & Cw & $\mathrm{DR}$ & DRw & $\mathrm{DQ}$ \\
\hline $\mathrm{a}$ & 2 & 63 & (Bw4) & 7 & 14 & 52 & 5 \\
\hline \multirow[t]{2}{*}{ b } & 1 & 57 & (Bw4) & 6 & 4 & 53 & 8 \\
\hline & DRB1* & DRB3* & DRB4* & DRB5* & DQB1* & DPB1* & \\
\hline $\mathrm{a}$ & $14 X X$ & $01-03$ & & & $05 X X$ & & \\
\hline b & $04 X X$ & & 01 & & $03 X X$ & & \\
\hline \multirow[t]{2}{*}{ Sibling $1 / 2$} & $(\mathrm{M})$ & & & & & & \\
\hline & A & B & & $\mathrm{Cw}$ & $\mathrm{DR}$ & DRw & $\mathrm{DQ}$ \\
\hline a & 2 & 63 & (Bw4) & 7 & 14 & 52 & 5 \\
\hline \multirow[t]{4}{*}{ c } & 33 & 14 & (Bw6) & & 1 & & \\
\hline & DRB1* & DRB3* & DRB4* & DRB5* & DQB1* & DPB1* & \\
\hline & $14 X X$ & $01-03$ & & & $05 X X$ & & \\
\hline & $01 X X$ & & & & & & \\
\hline \multirow[t]{7}{*}{ Sibling 2/1 } & (M) & & & & & & \\
\hline & A & B & & $\mathrm{Cw}$ & $\mathrm{DR}$ & DRw & $\mathrm{DQ}$ \\
\hline & 11 & 51 & (Bw4) & 6 & 4 & 53 & 3 \\
\hline & & 13 & (Bw4) & & 7 & 53 & 2 \\
\hline & DRB1* & DRB3* & DRB4* & DRB5* & DQB1* & DPB1* & \\
\hline & $04 X X$ & & 01 & & $03 X X$ & & \\
\hline & $07 X X$ & & 01 & & $02 X X$ & & \\
\hline \multirow[t]{7}{*}{ Sibling 2/2 } & (M) & & & & & & \\
\hline & A & B & & $\mathrm{Cw}$ & $\mathrm{DR}$ & DRw & $\mathrm{DQ}$ \\
\hline & 1 & 8 & (Bw6) & 7 & 4 & 53 & 3 \\
\hline & & 51 & (Bw4) & & 15 & 51 & 6 \\
\hline & DRB1* & DRB3* & DRB4* & DRB5* & DQB1* & DPB1* & \\
\hline & $04 X X$ & & 01 & & $03 X X$ & & \\
\hline & $15 X X$ & & & 01-02 & $06 X X$ & & \\
\hline
\end{tabular}

The 1st siblings share a haplotype. The 2nd siblings share only some of the HLA antigens (HLA-B51, DR4, DRw53, DQ3); without family typing it is not possible to prove, that those were inherited from the same parent

DNA polymerase (Abgene, Epsom, Surrey, UK) was used for catalysing the PCR reaction [4]. Results and clinical data are shown in Table 1-3. Genetic testing of siblings was carried out with their informed consent.

\section{Results}

The siblings had identical light chain or heavy chain secretion or both and both had been exposed to known mutagens in their first 20 years of life (Table 1). Although blood group $B$ was present in two of the four persons it 
Table 3. GST metabolizing enzyme polymorphism results.

\begin{tabular}{l|lll}
\hline & GSTT1 & GSTM1 & GSTP1 \\
\hline \hline $1 / 1$ & 0 & 0 & lle/Val \\
$1 / 2$ & 1 & 1 & le/Val \\
$2 / 1$ & 1 & 0 & le/lle \\
$2 / 2$ & 1 & 0 & lle/le \\
\hline
\end{tabular}

Sibling 1/1: GSTT1/ GSTM1 null and GSTP1 Ile/Val ;Sibling $1 / 2$ GSTT1 / GSTM1 heterozygote and GSTP1 Ile/Val; Sibling 2/1 and 2/2: GSTT1 heterozygote and shared GSTM1 null / GSTP1 lle/ Ile. Interestingly Siblings 2/1 and 2/2 had identical polymorphisms concerning all the metabolic enzymes tested and siblings $1 / 1$ and $1 / 2$ were identical only in the homozygozity in the GSTP1 polymorphism

has previously been pointed out that is not the case in a large cohort of MM patients [5]. Karyotype analysis showed only a single alteration (gain of chromosome 11) in sibling $2 / 2$.

Sibling pair 1 shared a haplotype. Sibling pair 2 shared only HLA-B51, DR4, DRw53, DQ3 (Table 2). Metabolizing enzyme polymorphism results indicated that Sibling $1 / 1$ was GSTT1 / GSTM1 null and GSTP1 Ile105Val; Sibling 1/2 was a GSTT1 / GSTM1 heterozygote and GSTP1 Ile105Val; Sibling 2/1 and 2/2 were GSTT1 heterozygotes and shared GSTM1 null / GSTP1 Ile105/le (Table 3). Both siblings had wild type for H63D and C282Y polymorphism of the HFE gene (not shown).

\section{Discussion}

In the process of carcinogenesis environmental genotoxic exposures and inherited susceptibility may overcome defence mechanisms such as DNA repair and tumor suppressor gene activities. Recently it has been proposed that diseases developing in the elderly evolve because of failure of the ageing protective mechanisms rather than because of the accumulation of toxic compounds $[6,7]$. In this study we point on that this might be only one possible explanation among many, emphasizing the importance of inherited traits and environmental exposures endured in early youth.

The sad example of secondary leukemia is evidence that cytostatics that form DNA adducts can induce prolonged sister chromatid exchange (SCE) induction and so contribute to leukemic transformation, in contradistinction to those compounds that are negative in the so-called SCE test [8]. These findings would support the concept of agent-specific carcinogenesis. In the following discussion we reflect on the question from the point of view of inherited defence mechanisms provided by human metabolic enzymes.
The enzymes of the glutathione S-transferase system (GST) catalyze the conjugation of compounds of carcinogenic potential rendering them less toxic. Genes coding for the GST mu I (GSTM1), theta 1 (GSTT1) and GSTP1 metabolizing enzymes are polymorphic in humans, and in the case of the "null phenotype" this preventative activity is absent. Concerning GSTP1 a single nucleotide polymorphism (Ile105Val) results in a variant enzyme with lower thermal stability and altered catalytic activity. However, the literature discussing the relationship of enzyme polymorphism and disease development is controversial. In cohorts of 58 and of 86 MM patients there was no difference in the polymorphism of these detoxifying enzymes in comparison to the average population $[9,10]$. In contrast, according to the study of Lincz et al. there was a higher incidence (22 of 68) of GSTT1 null genotype in cases of multiple myeloma than in controls (29 of 176) [11]. Others have found that alterations in enzyme polymorphisms lead to significant differences in drug availability, consequently in drug effectiveness and therefore in prognosis [12].

The inherited defect in the hemochromatosis gene (HFE) causing iron overload confers oxidative stress to tissues predisposing them to malignant transformation [13-15]. In our present study the two pairs of siblings examined were negative for C282Y and H63D mutations. This finding is in concordance with earlier results indicating that $\mathrm{MM}$ patients are less involved in this polymorphism than the average population $[16,17]$.

What is it then that predisposes families to the development of this B-cell clonal disease? And why do not all family members acquire the disease? Moreover, is there any inherited characteristic known to be associated with the development of multiple myeloma at all?

HLA associations were studied to try to answer these questions.

Grobois B. reported on 15 MM families. One pair of siblings who had been HLA typed were identical in A1, A2, B15, B41 antigens. In another report, the same author introduced two brothers who were completely identical in A2, B12, BfS, DR4, B27BFS, DR2GLo1 antigens $[18,19]$. Engelhardt $M$. et al. found a high incidence of monoclonal B-cell diseases in the siblings of patients with MM who were offering themselves as allogeneic donors. The prevalence of monoclonal B-cell disease in asymptomatic siblings of myeloma families was $29,6 \%$. HLA-A9 was present in 3 out of 5 families where all the siblings had monoclonal B-cell disease [20]. In a cohort of 125 MM patients, thirty had 39 relatives suffering from several tumors and $28 \mathrm{MM}$ patients had second primary malignancies as well. A 40-fold tumor incidence increase in MM families was found in contrast to the average population [5]. 
There are many other studies presenting examples of familial occurrence of hematological malignancies [21-23].

Studies in unrelated MM have shown significant association of Cw2 or B18 alleles to the process [24,25]. These data reflect the fact that although there is not really a general disease-specific HLA profile for MM, in certain cases the similarities or differences in the HLA antigens might be important to better the understanding of the disease.

\section{Conclusions}

Similarities found in siblings concerning the GSM1, GST1 or GSTP1 metabolizing enzyme genes or HLA markers are not surprising. In the first twenty years of life, staying in the same environment will probably lead to similar

\section{References}

[1] Staff I. NIH lymphocyte microcytotoxicity technique. In: Manual of Tissue Typing Technique, Bethesda 1976; 22-24

[2] Olerup O, Zetterquist H. HLA-DR typing by PCR amplification with sequence-specific primers (PCRSSP) in two hours: an alternative to serological DR typing in clinical practice including donorrecipient matching in cadaveric transplantations. Tissue Antigens 1992, 39, 225-232

[3] Lin DX, Tang YM, Peng Q, Lu SX, Ambrosone CB, Kadlubar FF. Susceptibility to esophageal cancer and genetic polymorphisms in glutathione S-transferases T1, P1 and M1 and cytochrome P450 2E1. Cancer Epidemiol Biomarkers Prev 1998, 7, 1013-1018

[4] Ozawa S, Schoket B, McDaniel LP, Tang YM, Ambrosone CB, Kostic SZ, Vincze I, Kadluber FF. Analyses of bronchial bulky DNA adduct levels and CYP2C9, GSTP1 and NQO1 genotypes in a Hungarian study population with pulmonary diseases. Carcinogenesis. 1999, 20, 991-995

[5] Varkonyi J, Kovalszky I, Nemeth A, Demeter J, Raposa T. Increased risk for cancer in multiple myeloma patients and their first-degree relatives. Haematologia 2001, 31, 45-50

[6] Lynch HT, Sanger WG, Pirucclle S, Quinn-Laguer B, Weisenburger DD. Familial multiple myeloma: A family study and review of the literature. $\mathrm{JNCl} 2001$, 93, 1479-83

[7] Sobol H, Vey N, Sauvan R, Philip N, Noguchi T, Eisinger F. Re: Familial multiple myeloma: a family study and review of the literature. JNCI 2002, 94, 461-462 disease characteristics in siblings. In the development of $\mathrm{MM}$, as in the case of other malignancies, the type of exposure, the inborn features of metabolism and repair mechanisms are equally important factors. From these family studies one might emphasize the importance of chronic carcinogen exposure endured in early years of life in the etiology of a disease manifesting in the elderly. In concordance with previous studies we might also conclude that the development of MM in siblings is not especially more frequent than that of other malignancies in the patients' family, but significantly more than that experienced in the average population. The authors therefore suggest patient and family screening for cancers, emphasizing the importance of early detection and prevention by changing lifestyle to avoid genotoxic exposure as much as possible.

[8] Raposa T, Várkonyi J. Leukemogenic risk prediction of the cytostatic treatment. In: Mutation and Environment, Part D. Carcinogenesis. Progr. Clin. Biol. Res. 340: 53-63. Eds.: M.L. Mendelshon and R.J. Albertini. Wiley-Liss Inc., 1990, New York

[9] Ortega MM, Nascimento $H$, Melo M, Teori MT, Costa FF, Lima CSP. Polymorphism of glutathione S-transferase Mu1 (GSTM1) and Theta1 (GSTT1) genes in multiple myeloma. Acta Haematol 2003, 109, 108-109

[10] Várkonyi J, Szakály D, Jánoskúti L, Hosszúfalusi N, Pánczél P, Karádi I, Mikala G, Tordai A, Schoket B. Metabolizing enzyme polymorphism studies in multiple myeloma. Turkish Journal of Haematology 2005; 22(S); Abstr.No.104. XXXth World Congress of the International Society of Hematology September 28-October 2, 2005. Istanbul

[11] Lincz LF, Kerridge I, Scorgie FE, Bailey M, Anno A, Spencer A. Xenobiotic gene polymorphisms and susceptibility to multiple myeloma. Haematologica 2004, 89, 628-629

[12] Dasgupta RK, Adamson PJ, Davies FE, Rollinson S, Roddam PL, Ashcroft AJ, Dring AM, Fenton JAL, Child JA, Allan JM, Morgan GJ. Polymorphic variation in GSTP1 modulates outcome following therapy for multiple myeloma. Blood. 2003, 102, 2345-2350

[13] Nelson RL, Davis FG, Persky V et al. Risk of Neoplastic and other diseases among people with heterozygozity for hereditary hemochromatosis. Cancer 1995, 76, 875-879

[14] Haliwell B, Gutterdige JMC. Role of free radicals J. 
Várkonyi et al. and catalytic metal ions in human disease: An overview. Methods Enzymol. 1990, 186, 1-85

[15] Loeb LA, James EA, Waltersdorph AM et al. Mutagenesis by autooxidation of iron with isolated DNA. Proc. Natl. Acad Sci USA 1988, 85, 3918-3922

[16] Franchini M, Veneri D. Iron overload and hematological malignancies. The Hematology Journal 2004, 5, 381-38

[17] Várkonyi J, Demeter J, Tordai A, Andrikovics H. The significance of the Hemochromatosis genetic variants in Multiple Myeloma in comparison to that of Myelodysplastic syndrome. Ann Hematol. 2006, 85, 869-871

[18] Grobois B, Jego P, Attal M, Payen C, Rapp MJ, Fuzibet JG, Maigre M, Bataille R. Familial multiple myeloma: report of fifteen families. Brit J Haematol 1999, 105, 768-770

[19] Grobois B, Gueguen M, Fauchet R, Lebouc $H$, Guenot A, Lancelin F, Lauvin R, Leblay R, Genetet B. Multiple myeloma in two brothers. Cancer 1986, 58, 2417-2421

[20] Engelhardt M, Ihorst G, Behringer D et al. Incidence of monoclonal B-cell disease in siblings of patients with multiple myeloma. Haematologica 2005, 91, 274-276
[21] Capalbo S, Trerotoli P, Ciancio A, Mele G, Serio $\mathrm{G}$, Liso V. Increased risk of lymphoproliferative disorders in relatives of B-CLL patients. Blood 1998; 92(S1): Abstr 4124

[22] Jakó J, Szerafin L, Nagy P, Simon Á, Kappelmayer J. Familial malignant blood diseases: lessons learned from a 20-year period. Leukemia Lymphoma 2004, 45, 109-111

[23] Shoenfeld $Y$, Berliner S, Shaklai M et al. Familial multiple myeloma. A review of thirty-seven families. Postgraduate Medical Journal 1982, 58, 12-16

[24] Pottern LM, Gart JJ, Nam JM et al. HLA and multiple myeloma among black and white men: evidence of a genetic association. Cancer Epidemiol Biomarkers Prev 1992, 3, 177-182

[25] Patel M, Wadee AA, Galpin J, Gavalakis C, Fourie AM, Kuschke RH, Philip V. HLA class I and class II antigens associated with multiple myeloma in southern Africa. Clin. Lab. Haem. 2002, 24, 215-219 